Gifts as Economic Signals and Social Symbols

Author(s): Colin Camerer

Source: The American Journal of Sociology, Vol. 94, Supplement: Organizations and Institutions: Sociological and Economic Approaches to the Analysis of Social Structure (1988), pp. S180-S214

Published by: The University of Chicago Press

Stable URL: http://www.jstor.org/stable/2780246

Accessed: 14/02/2011 18:43

Your use of the JSTOR archive indicates your acceptance of JSTOR's Terms and Conditions of Use, available at http://www.jstor.org/page/info/about/policies/terms.jsp. JSTOR's Terms and Conditions of Use provides, in part, that unless you have obtained prior permission, you may not download an entire issue of a journal or multiple copies of articles, and you may use content in the JSTOR archive only for your personal, non-commercial use.

Please contact the publisher regarding any further use of this work. Publisher contact information may be obtained at http://www.jstor.org/action/showPublisher?publisherCode=ucpress.

Each copy of any part of a JSTOR transmission must contain the same copyright notice that appears on the screen or printed page of such transmission.

JSTOR is a not-for-profit service that helps scholars, researchers, and students discover, use, and build upon a wide range of content in a trusted digital archive. We use information technology and tools to increase productivity and facilitate new forms of scholarship. For more information about JSTOR, please contact support@jstor.org. 


\title{
Gifts as Economic Signals and Social Symbols ${ }^{1}$
}

\author{
Colin Camerer \\ University of Pennsylvania
}

\begin{abstract}
Gift-giving has often puzzled economists, especially because efficient gifts-like cash or giving exactly what a person asks forseem crass or inappropriate. It is shown in a formal game-theoretic model that gifts serve as "signals" of a person's intentions about future investment in a relationship, and inefficient gifts can be better signals. Other explanations for the inefficiency of gift giving are advanced, and some stylized facts about gift-giving practices are described (many of which are consistent with the signaling view of gifts).
\end{abstract}

People give others gifts, which are often reciprocated. Appropriate gifts are often inefficient: givers buy goods different from those receivers would like. These practices, especially the inefficiency of gifts, are a little puzzling to economists.

\section{The Anthropological Approach}

A distinguished line of anthropologists has been interested in gift giving (Boas 1895; Malinowski 1922; Mauss 1967), perhaps because of the extravagance and importance of gift-giving rituals in primitive societies. The "potlatches" of coastal cultures in northwestern North America are typical (Boas 1920; Barnett 1938); Clyde Belshaw (1965) says a potlatch is a "complex institution of ceremonial wealth accumulation," centered on the numaym, "essentially a spatrilineal descent group with several welldefined corporate functions." Once admitted into the numaym, people give gifts to others, but repayment is expected, at huge interest rates. By "lending" to others through gift giving, people can build up enormous wealth. On ceremonial occasions, "the greatest potlatchers" would "dem-

${ }^{1}$ Thanks to Andrew Daughety, Mary Douglas, Gerry Faulhaber, Jack Hirschleifer, Howard Kunreuther, George Loewenstein, Ari Vepsalainen, Keith Weigelt, and the editors and referees of this supplement for encouragement and comments. Requests for reprints should be sent to Colin Camerer, Decision Sciences Department, The Wharton School, University of Pennsylvania, Philadelphia, Pennsylvania 19104.

(C) 1988 by The University of Chicago. All rights reserved.

$0002-9602 / 89 / 9407-0012 \$ 1.50$ 
onstrate how rich and magnificient they are by destroying their most valued items" (cf. Veblen [1934] on "conspicuous consumption" and Thompson [1979, chap. 9] on hog exchange in New Guinea). The potlatch and similar orgies of gift giving suggest that primitive gift giving helps clarify social roles, wealth, or status. Gifts may serve similar social functions in modern societies, but modern mechanisms may serve these functions even better (e.g., general consumption; see Douglas and Isherwood 1978).

In most anthropological accounts, reciprocity is essential-accepting a gift implies a solemn obligation of repayment (as in accepting a loan). This insistence on reciprocity suggests that, for primitives, gifts actually provide insurance or credit, ${ }^{2}$ substituting for exchange in formal, anonymous markets (see Posner 1980; Hemenway 1984). If so, the flamboyant gift giving chronicled by anthropologists is not a good guide to modern gift giving, and it is especially misleading to assume that modern gift giving must be reciprocal (it is not always so), as many scholars have (e.g., Schwartz 1967, p. 8; Titmuss 1971, p. 72; Akerlof 1982, p. 550).

\section{The Sociological Approach}

Sociologists have typically expanded the view of anthropologists that gifts symbolize and convey meaning. Indeed, gifts might serve many social functions (see, e.g., Schwartz 1967), including conveying identity, controlling and subordinating, conveying unfriendliness, reducing status anxiety, enforcing distributive justice, providing suspense or insulation, defining group boundaries, and atoning for unseen social deviations.

\section{The Economic Approach}

In the simplest theory of consumer choice, there is no place for the sort of inefficient gift giving we routinely observe between people; if consumers know their own tastes and markets function smoothly, givers should give cash (if anything) rather than trying to guess the desires of receivers. But this prescription seems to betray the spirit of gift giving.

We might "explain" the behavior of givers of inefficient gifts, in their utility functions, by supposing a distaste for giving cash, by supposing a wife's utility function contains her husband's utility as an argument, or by positing educational motives-perhaps a giver knows more about a recipient's tastes, current or future, than the recipient does (as with practical gifts to children). Or we can blame transaction costs and market failure,

${ }^{2}$ That is, gifts are like loans in primitive societies, but loans from modern banks are not like gifts. 
since, as Hemenway (1984, p. 54) notes, "On a trip I might see something unusual and inexpensive that a good friend might like. Buying it as a gift could prove more efficient than any available market arrangement." In an ongoing relationship, gifts might be tokens used to achieve equity or settle contracts after ex post observation of ex ante unobservables (cf. Fama 1980, on managerial contracts), but why use inefficient gifts as tokens? "Because gifts are more pleasant to receive" is an observation not an explanation. These economic explanations seem hollow and tautological. Furthermore, they offer no positive explanations for institutions of gift giving (such as holidays), and they do not squarely confront the question of inefficiency.

In this article, I begin with the sociologists' observation that gifts are symbolic of some qualities of gift givers or receivers; gifts are actions people take that convey meaning. In the terminology of information economics, such meaningful actions are "signals" (Spence 1974; see also Rothschild and Stiglitz 1976). A "signaling equilibrium" results when expectations about what signals mean are fulfilled by behavior.

The important difference between the economists' use of the term "signal" and the sociologists' use of the term "symbol" is that economic signals mean something because people who do not have the characteristics the signals convey cannot afford those signals, by definition. (If they could, the signals would no longer mean anything.) Education is an example. A college degree signals intelligence (and many other qualities) because college degrees are too difficult for unintelligent people to get. If degrees were easy to get, they would not mean anything about intelligence. Defining signals in this way makes them amenable to economic analysis of models in which agents choose signals to convey information that makes them more productive and happier.

One signaling explanation of inefficient gift giving is described and formalized in the next section, and several related explanations are advanced. After that, some general observations about modern conventions of gift giving are described, including some facts that are not consistent with the signaling view. The last section is a conclusion.

\section{GIFTS AS SIGNALS}

The argument that gifts are signals applies best to courtship between unrelated strangers-for example, potential spouses or business partners (including organizations). ${ }^{3}$ The signaling explanation is not especially

${ }^{3}$ For example, anthropologist Marcel Mauss (1967, p. 71) wrote: "The payments to chiefs . . . are for the most part counter-prestations made not solely in order to pay for goods and service, but also to maintain a profitable alliance which it would be unwise 
helpful in explaining gift giving between groups of people or charitable gift giving by individuals or organizations (see, e.g., Titmuss 1971; Arrow 1972; Kurz 1978).

Consider an earnest young suitor, expecting a lifetime of familial production with his fiancée (given her consent); he will gladly "sink" the costs of a diamond ring and expensive dinners against the expected gains of joint production, if he must, to convince her of his intentions and elicit her cooperation. The lusty bachelor whose planning extends only to dawn cannot afford such costly investments, ceteris paribus, since he expects less gain from a short-term relationship with his lady of that evening.

In courtship situations like this, gift giving can sort potential partners according to their intentions (i.e., their investment plans). Furthermore, gift giving will often be reciprocal (though not always), because gifts are meant to spur investments that are reciprocal. However, the reciprocity involved here is very different from the reciprocity that is so important in anthropological accounts. Potential mates or partners hope courtship gift giving is reciprocal, because in my model it takes two people to make a relationship. In the anthropological accounts, reciprocity is important because gifts are like loans rather than signals.

Because gift giving is often reciprocal, inefficient gifts that are not worth much to the receiver may be better signals than efficient gifts, since they help signal the receiver's intentions. Accepting an overpriced dinner instead of its cash equivalent has an opportunity cost to the receiver; so, incurring that cost is simultaneously a signal of the giver's intentions and of the receiver's intentions. (This is shown more formally below.)

\section{A Biological Analogy}

The clever account of animal gift giving by Dawkins (1976) is so remarkably like the signaling model of human gift giving during courtship that it is worth detailing. Like most sociobiological stories, the argument begins with selfish genes reproducing themselves as swiftly as possible. Genes that devise ingenious ways for surviving or propagating come to dominate in number. We then suppose that observable animal features, and perhaps social behavior, must have evolutionary value or else they would not have survived (though this reasoning can be tautological, as Lewontin [1979] warns).

The animal "battle of the sexes" is a simple conflict: "Each individual wants as many surviving children as possible. The less he or she is obliged

to reject, as for instance partnership between fishing tribes and tribes of hunters and potters." This is exactly the signaling argument, in a primitive setting where tribes signal between each other as people do. 
to invest in any one of those children, the more children he or she can have. The obvious way to achieve this desirable state of affairs is to induce your sexual partner to invest more than his or her fair share of resources in each child, leaving you free to have other children with other partners." Dawkins explains that males can often impregnate females and leave because a female, thus placed in a cruel bind, must raise the child alone or else watch it die. She will raise the child. So, "the things which a female might do if she is deserted by her mate . . . all have the air of making the best of a bad job. Is there anything a female can do to reduce the extent to which her mate exploits her in the first place? She has a strong card in her hand . . . the dowry of a large, nutritious egg. A male who successfully copulates gains a valuable food reserve for his offspring. The female is potentially in a position to drive a hard bargain before she copulates" (my emphasis). The "hard bargain" that females drive, according to Dawkins, is the screening of suitors for fidelity and domesticity by "insisting on a long engagement period" and engaging in courtship rituals that "often include considerable pre-copulation investment by the male." The male's gifts might include building a nest or feeding the female a lot of food.

Dawkins shows that an "evolutionary stable equilibrium" (Maynard Smith 1974) is reached if some fraction of the female population is "coy" and demands gifts and other females are "fast" and require no investment; whereas some males are "philanderers" who lose patience with mates who demand gifts, and other "faithful" males patiently offer gifts while waiting to copulate. An equilibrium exists when no type of animal (or gene) can increase its proportion of the population.

\section{A Formal Model}

A game-theoretic model can show how costly and inefficient gifts must be to signal effectively. The casual reader can skip ahead to the next section, and the avid reader can find technical details in the Appendix.

We start with two players, 1 and 2-prospective mates or business partners-who choose separately whether to "invest" $(I)$ or "not invest" $(N)$ during a fixed period. Investment includes purchases of household goods, psychological or physical sacrifices, time spent building a relationship or raising children, and so forth. Since this investment is slippery to define, contracts are obviously not enforceable, and we assume that players do not know whether their partner has invested until after the period is over. (We can define a period as that length of time that elapses before a lack of investment can be detected.) Since both investments affect players' utilities, there are four possible levels of investment-related utility for each player. Assume there are only two patterns of these four utilities: 
"willing" $(W)$-type players prefer investing if their partner invests, but "unwilling" $(U)$-type players always prefer not to invest.

That is, setting the no-investment utility $V(N, N)=0$ as a benchmark and using the following general notation (shown for a $W$-type player 1 ),

$$
\begin{gathered}
V_{1}^{W}(I, I)=R(W) \quad \text { Romance, } \\
V_{1}^{W}(N, I)=C(W) \quad \text { Cheating, } \\
V_{1}^{W}(I, N)=Q(W) \quad \text { unreQuited love, }
\end{gathered}
$$

then an implicit definition of players' types is simply

$$
\begin{aligned}
& R(W)>C(W)>0>Q(W) \\
& C(U)>R(U)>0>Q(U) .
\end{aligned}
$$

That is, $W$-type players prefer romance to cheating (they will invest only if the other invests), and $U$-type players prefer cheating to romance (they will not invest, even if the other invests). Both kinds of players like $Q$ least of all.

The investment game. - With payoffs thus defined, we can model the investments of the courting partners as a one-period, noncooperative game, which means that players cannot communicate about and enforce their choices of strategies and they cannot give gifts or convey their willingness.

In this simple investment game, unwilling players never invest (by definition), and both willing players invest if and only if their expected values from investing are above their expected values from not investing (see App.). Define the prior probabilities of willingness as $P_{1}$ and $P_{2}$. (These could be interpreted as the chances that the players willingly invest until they reach some milestone, such as having a month-long relationship, becoming intimate, or getting engaged or married.) Intuitively, when willing player 1's invest, they trade off the expected benefit $P_{2} R(W)$ against the expected loss $\left(1-P_{2}\right) Q(W)$ and the opportunity cost of not investing, $P_{2} C(W)$. They prefer to invest only if $P_{2}$ is above an investment threshold, which depends on $R(W), Q(W)$, and $C(W)$.

More formally, the game is a noncooperative game of imperfect information, because, contrary to the assumption made in much of game theory, players do not have the same information about the game: they each know their own types. John Harsanyi (1967-68) argues that it is logical to model such "games of incomplete information" by assuming that there are some things not everybody knows ("private information") but that everybody knows ${ }^{4}$ the probability distribution of exactly what

4 "Everybody knows" is formalized in game theory as "common knowledge" (Lewis 1969; Aumann 1976). 
that private information is. In this case, we suppose players know their own types, and the probability that their partner is a willing type. Then, an elaborate game is played in which players choose from contingency strategies that specify a choice for all the possible types a player might be. These will be strategies of the sort "If willing, choose $I$; if unwilling, choose $N$," written $(W, I ; U, N)$. For a simultaneous noncooperative choice of two contingency strategies, the payoffs are the expected values of the possible utility outcomes in definitions (1)-(3), weighted by the probability that each outcome will result.

Since players are assumed not to communicate and to choose simultaneously, we search for Nash equilibria-pairs of strategies, one for each player, that are best responses for both. ${ }^{5}$ The strategies described above-unwilling players never invest, willing players invest only if both probabilities $P_{1}$ and $P_{2}$ are above their investment thresholds-are a unique Nash equilibrium.

Why signaling is needed.-Players will not invest early in a relationship, when either $P_{1}$ or $P_{2}$ is low (and below the investment threshold), or before an important commitment, when $Q(W)$ is especially large (so that the probability threshold is large). However, players will invest if they can somehow discover a partner's willingness. Biological predictors and verbal pleas are notoriously unreliable (because they are not hard to fake), so partners need an indicator that is too costly to fake-a signal. ${ }^{6}$ These signals do not necessarily have to be personal gifts, but gifts will work very well because the gift givers are known to the recipients (unless they are given by secret admirers), as we require in our analysis of the game, and gifts clearly mark the informational purpose and target of the signal. Thus, we shall now allow players to communicate in a very limited way by deciding simultaneously, and without further communication, whether or not to give gifts before any investment takes place.

I define $G_{1}$ and $G_{2}$ as the signaling costs to players 1 and 2 in income, time, and so on. ${ }^{7}$ I define "efficiency" $e_{1}$ as the marginal utility of player 2's gifts to receiver 1 (and I define $e_{2}$ similarly). Efficient or practical gifts-cash or a gift chosen by the receiver-will have $e_{1}=1$, because

${ }^{5}$ That is, $(X, Y)$ is a Nash equilibrium if and only if $X$ is player 1's best response to the hypothesized choice of $Y$ by player 2, and $Y$ is player 2's best response to the hypothesized choice of $X$ by player 1 . See, e.g., Luce and Raiffa (1957).

${ }^{6}$ This signal is actually quite different from nest building and other animal behavior discussed by Dawkins (1976). In his model, all animals are assumed to be unwilling, and requiring gifts imposes a marginal cost that makes desertion uneconomical. In my model, requiring a gift signals willingness, and willing human animals will even volunteer to give gifts to distinguish themselves from unwilling heartbreakers.

${ }^{7}$ So, $L_{1} G_{1}$ and $L_{2} G_{2}$ are the costs of the signals in utility terms-the income cost times the marginal utility of income $L_{1}$ or $L_{2}$. For simplicity, I drop the marginal utility of income terms in the analysis. 
given free choice receivers will pick gifts that have a marginal utility equal to the marginal utility of income. Frivolous gifts will have $e_{1}=0$, since they generate no marginal utility, and "unfriendly" gifts (see Schwartz 1967, p. 5) may even have negative values of $e_{1}$. The puzzle I seek to explain is why it seems necessary for $e_{1}$ to be less than one for a gift to signal a person's intentions appropriately.

The two-stage signaling-investment game.- - Signaling makes the courtship game a two-stage game. In the first stage, players choose a "contingency strategy" of the form $\left(W, G_{1} ; U, 0\right)$, which dictates whether or not they would invest in the signal (give gifts) if they were each possible type. Then, knowing their actual type, they execute the contingency strategy applied to their actual type. After seeing their partners' signals (or lack thereof) and knowing the equilibrium contingency strategy, each player updates his or her information about the partner's type. Then players choose whether to invest in the second (investment) stage. The payoffs that players anticipate, and on the basis of which they choose their twostage strategies, are the total payoffs from both stages of the game.

\section{Equilibria in the Two-Stage Gift-giving Game}

In this two-stage game, there are many equilibria, depending in idiosyncratic ways on the exact values of the probabilities and utilities. Figure 1 summarizes the results (see the App. for details). If $C(W)<C(U)$ (unwill-

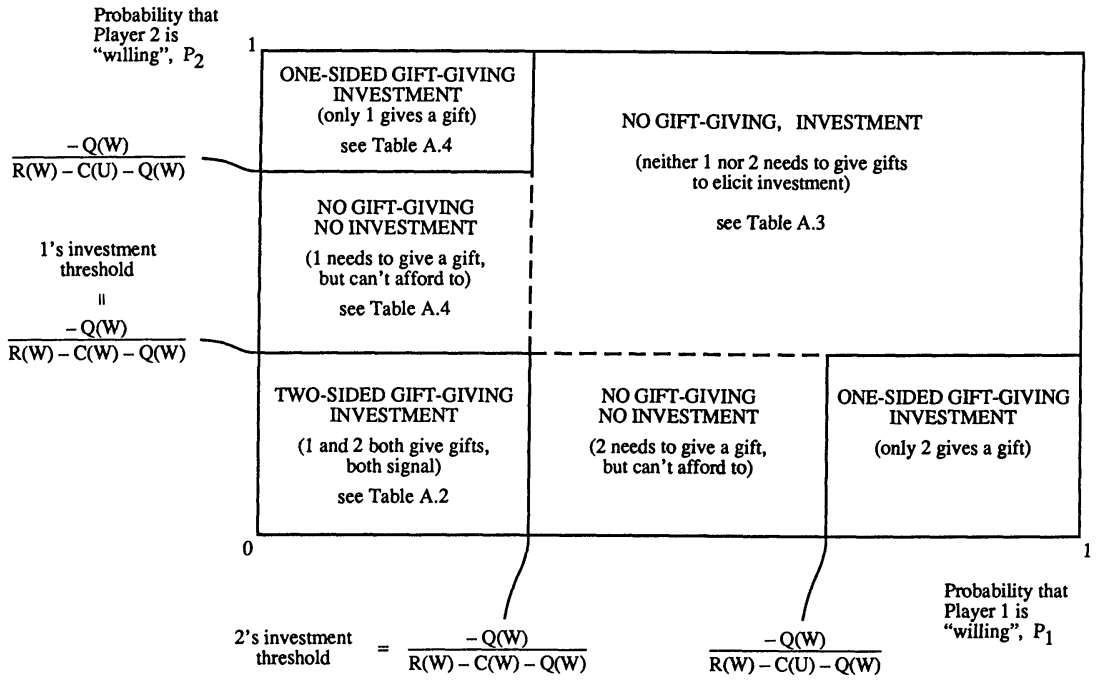

Fig. 1.-Bayesian Nash equilibria, noncooperative gift-giving, investment game (assuming $C(W)<C(U)$ ). 
ing cheaters are happier than willing cheaters), as seems most likely, then there are four kinds of equilibria: ${ }^{8}$

1. If both probabilities $P_{1}$ and $P_{2}$ are below the investment thresholds from the one-stage investment game, players know that no investment will take place unless willing types distinguish themselves by signaling. Thus, "two-sided gift giving" is the unique Nash equilibrium. Both players give gifts, if willing, and unwilling players do not. If a gift is received, a player can infer that the partner is willing, so a willing partner then invests. (This "separating" equilibrium enables a willing player whose love is unrequited by an unwilling partner to find that out after wasting only a gift, rather than wasting a more expensive investment.)

2. If both probabilities $P_{1}$ and $P_{2}$ are above the investment thresholds, "no gift giving, investment" is the equilibrium. Players do not need to give gifts in order to elicit investment from a partner, and giving gifts does not elicit any additional investment or prevent cheating by an unwilling partner, so neither player gives a gift.

3. If one probability is moderately high $\left(\boldsymbol{P}_{1}\right.$, say) and the other probability is below the investment threshold, then the low-probability player 2 needs to give a gift to win player 1's trust, but player 2 cannot afford to (even if he is willing) because the required gift is too expensive. (That is, player 2 earns a negative net return after buying the gift, signaling his type, and then earning either $R[W]$ or $Q[W]$. He would prefer not to play and to earn nothing.) Hence, a "no signaling, no investment" equilibrium results. (If $C[U]<C[W]$, this equilibrium never occurs because the gift is affordable to any player whose probability is above the investment threshold.)

4. If one probability is very high $\left(P_{1}\right.$, say) and the other probability is low, then the low-probability player 2 can afford the gift. A "one-sided gift-giving, investment" equilibrium results in which only the lowprobability player gives a gift. The difference between this equilibrium and the no-signaling equilibrium in (3) is that if $P_{1}$ is high, then player 2 can give the gift and expect a high-enough probability of $R(W)$ and a lowenough probability of $Q(W)$ to make the net return positive. In (3), the probability of $R(W)$ is too low, and the probability of $Q(W)$ is too high.

In the Appendix, I analyze the gift-giving game played cooperativelythat is, when the players agree on enforceable joint strategies. The cooperative game has almost exactly the same result as the noncooperative game, except that the equilibrium always involves two-sided gift giving (followed by investment by willing players), regardless of the levels

${ }^{8}$ If $C(W)>C(U)$, then the "two-sided gift-giving" region in fig. 1 expands outward, completely engulfing the "no gift-giving, no investment" regions and expanding into the "one-sided gift-giving, investment" and "no gift-giving, investment" regions. 
of probabilities. The difference between the various noncooperative results (depicted in fig. 1) and the single cooperative result is that in the noncooperative game players move unilaterally, taking their partners' moves as fixed. Thus, players will selfishly refrain from gift giving if they expect others to give gifts. In the cooperative game, essentially, players move together, and, since it is always an improvement for willing players to give gifts (if both could only agree to do so), they will do so in the cooperative game, even if they cannot agree to do so in the noncooperative game. ${ }^{9}$

The cost and efficiency of equilibrium gifts.-For the gift-giving equilibria to hold, the cost of the gift signals $G_{1}$ and $G_{2}$ must satisfy

$$
\begin{aligned}
& P_{2} R(W)>G_{1}>P_{2} C(U) \\
& P_{1} R(W)>G_{2}>P_{1} C(U) .
\end{aligned}
$$

That is, the cost of player 1's gift should exceed what an unwilling player 1 could expect to get $\left(P_{2} C[U]\right)$ by sneakily giving a gift, then cheating during the investment stage. But a gift should not be so expensive that it costs more than the willing player expects to get $\left(P_{2} R[W]\right)$ from signaling, then investing.

In the two-stage game, it does not matter what the efficiency levels are because, in a Nash equilibrium, each player takes the other's moves (including the gift giving) as given; so a willing player assumes he may get a gift regardless of whether he gives a gift. To introduce a role for efficiency, we can suppose there is an initial stage in which players must pay some minimal entry costs $T_{1}$ and $T_{2}$ to enter the two-stage signalinginvestment game of courtship. (These costs might include the costs of making a date or arranging an occasion for gift giving.) An unwilling player 1 can then pay the entry cost and earn a net expected value of $-T_{1}$ $+e_{1} G_{2} P_{2}$, because there is a $P_{2}$ chance his partner has paid the entry cost and will then give a gift with value $e_{1} G_{2}$. The unwilling player 1 can be deterred from participating at all (though willing players are not deterred; see App.), thus saving player 2 the cost of a wasted gift, if

$$
e_{1}<T_{1} / G_{2} P_{2}
$$

and, for player 2 ,

$$
e_{2}<T_{2} / G_{1} P_{1}
$$

These conditions place upper limits on how efficient (or "practical") gifts should be. Gifts can be somewhat practical, but they may not be too

${ }^{9}$ Because the cooperative game always enables partners to find partners through gift giving but the noncooperative game does not, it brings a new twist to Paul Samuelson's dictum that "cooperative game theory represents love in economics." 
practical, or else unwilling types will play the signaling game merely to collect gifts. At last, we have a formal explanation of why gifts need to be inefficient to signal intentions well.

Another explanation for efficiency arises if we force both types of players to give gifts of identical costs. Then the willing types will signal their types by asking for inefficient gifts, while unwilling types will ask for perfectly efficient gifts (see App. for details).

Inefficient gift giving is a double-edged sword, however: it protects the giver from gift collectors, but it also costs the willing giver the opportunity to receive gifts he really enjoys. Both players are happier exchanging the inefficient gifts in (8) and (9) only if (see App.)

$$
\left(1-P_{1}\right) / P_{1}>G_{1} / G_{2}>P_{2} /\left(1-P_{2}\right) \text {. }
$$

These inequalities reflect the tradeoff between the benefits of giving an inefficient gift (which deters) and the opportunity cost of receiving an inefficient gift (which is harmful). If the prior probabilities $P_{1}, P_{2}$ are small, then inefficient gift giving does more good (deterrence) than harm (opportunity cost), but, if the probabilities are large, as when a relationship is mature, giving inefficient gifts does more harm than good, and players prefer to exchange efficient gifts.

The optimal gift costs from (6) and (7) and the optimal efficiency levels from (8) and (9) paint a picture of the life cycle of gift giving that is somewhat familiar in courtship. On meeting, a nervous couple (with low probabilities of willingness) initially prefer to exchange inexpensive, inefficient gifts that have only sentimental value. Assuming that they gradually become more certain that their partners are willing (or else the relationship ends), they gradually give more expensive, more practical gifts. Eventually, perhaps, they simply buy themselves what they want with their partners' money.

\section{Complicating the Model}

Of course, the model is only a skeletal abstraction of actual gift giving. Usually, gift giving occurs in multiple rounds, in which successively more expensive, and perhaps more efficient, gifts are given. We could interpret these as equilibria of a game in which there are more than just two types, so that each successively more expensive gift serves to distinguish players from the several less-willing types they might have been. (Here, there is only one size gift because the willing types only have to distinguish themselves from one other type of less-willing player.)

Another complication is competitive gift giving. Often, people involve several suitors in bidding wars (or tolerate such wars). In my simple 
model, the $i$ th suitor's gift should $\operatorname{cost} P_{2}^{i}$ (the $i$ th suitor's assessment of the probability that the courted player 2 is willing to invest in suitor $i$ ) times $C_{i}(U)$ (the $i$ th suitor's gain from cheating). A suitor will give larger gifts if he $(a)$ is more confident that the courted player is in love with him or $(b)$ has more to gain by giving a gift and then cheating. Since the courted player is assumed to know whom he is in love with better than the suitors do, the only information that gifts convey is about the gains suitors would get from cheating. Perhaps a courted player should settle for the suitor who bids lowest (i.e., has the least to gain from cheating) not highest. Competitive gift giving probably signals wealth, or some other attribute, rather than willingness (though the wealth of a suitor might indeed affect the courted player's attitude toward the suitor).

\section{Interpreting the Equilibria as Conventions}

Of course, people do not actually court each other and give gifts in the artificial, abstract way depicted by the noncooperative game. It is better to think of the different equilibria pictured in figure 1 as social conventions that dictate what gifts (if any) are appropriate for what occasions, how expensive gifts should be, and so on. The conventional exchange of token gifts (flowers, special efforts in grooming or fashion) on initial dates may be an institutionalization of the two-sided signaling equilibrium when willingness is unlikely. Other rules of etiquette dictate when it is appropriate form for only one person to give a gift (as in my one-sided gift-giving equilibria). Lavish signaling usually takes place before important times, when heavy investment makes $Q(W)$ especially costly - as when a woman (and, less so, a man) expects a child, or when people start to live together or buy a house ${ }^{10}$ - because a larger $Q(W)$ raises the thresholds $t_{1}$ and $t_{2}$ and requires signaling for investment to take place. Social rules that prescribe gift giving might be thought of as cultural calculations of equilibria, which prescribe behavior even when individuals make no such calculations (cf. von Neumann and Morgenstern's "standards of behavior" [1953, pp. $31 \mathrm{ff}$.]).

\section{OTHER EXPLANATIONS FOR INEFFICIENCY}

Analysis of the noncooperative game in which players exchange gifts that indicate their willingness, then invest, yields the following results: (i) if

${ }^{10}$ For instance, housewarming presents are signals from friends and neighbors that the large burden of owning a house without help, analogous to $Q(W)$ in the courtship game, will be shared. 
the chances that partners will invest willingly in a relationship are large enough (relative to their costs and benefits), then no gift giving is needed; (ii) if the chances that both players will invest are low enough, reciprocal gift giving can signal players' types and ensure their investments; (iii) if one player's chance of investing is low and another's is sufficiently high, then only the low-probability player should give a gift to the highprobability player, and investment will then take place; and (iv) if there is some cost even to entering the gift-giving-investment game, then inefficient gifts will serve a useful purpose by discouraging unwilling players from entering the game. The game, while simple, begins to account for some of the basic stylized facts, since conclusion (iii) shows that reciprocity is not essential and conclusion (iv) provides a rationalization for inefficient gift giving.

In the formal model, impractical gifts are good because they deter unwillingly players from engaging in insincere gift giving simply to collect gifts. (And, even then, efficient gifts are preferred in mature relationships where probabilities of willingness are high.) This explanation may account for some instances of deliberately inefficient gift giving-when dates exchange trinkets during courtship, for instance-but the deterrence motive for inefficient gift giving does not ring true for many other kinds of gift giving (especially in mature relationships). Three other classes of explanations are now offered.

\section{Inefficiency as the Price of Multidimensional Gift Giving}

If the sheer cost of a gift signals something about the giver and the specific choice of gift signals something else, then the inefficiency of the specific gift is simply the social price one pays for buying gifts that signal more than one thing at once. ${ }^{11}$ Indeed, it would be a pleasant, rare surprise if gifts that are appropriately costly and convey the right message happen to be the gifts that receivers want.

Consider a large class of gifts that signal $\$ 50$ 's worth of willingness: $\$ 50$ in cash, a $\$ 50$ health-club gift certificate, $\$ 50$ in sushi, a $\$ 50$ bottle of wine, $\$ 50$ 's worth of underwear, $\$ 50$ 's worth of poetry, a $\$ 50$ subscription to Spin. Each gift in this class signals willingness equally well (\$50's worth), but each gift signals something else - tastes the giver has or hopes the receiver develops (Spin); how carefully the giver was listening when the receiver discussed food or wine (sushi, wine); or how much the giver appreciates the receiver's bodily (underwear) or intellectual (poetry) charms or thinks those bodily charms need maintaining (health club).

11 This is hinted at by Posner (1980, p. 25): "Notice that, viewed as a signaling device, a gift need not actually be received or enjoyed by the donee." 


\section{Inefficiency as the Price of Convention}

Many gifts signal things by convention (Lewis 1969) or custom (Akerlof 1980), and these conventional gifts are often inefficient. The cigars a proud father might distribute to signal the birth of a child are probably not smoked, nowadays, but they are unmistakable signals. ${ }^{12}$ Indeed, most gift giving between friends or distant relatives may be of this conventional sort.

Conventional gifts are not necessarily inefficient. When the practice of cigar giving began, for instance, probably most men did enjoy cigars. However, conventions arise to coordinate behavior among people who cannot communicate with one another easily (Lewis 1969), so when things change and a more efficient signaling convention becomes available, it is difficult, by the nature of conventions, to coordinate change from the old convention to a new one. A classic example is the QWERTY typewriter keyboard, which has not been widely replaced by the more efficient Dvorak keyboard (David 1985).

Thus, tradition rules by tyranny. If flowers are what well-intentioned gentlemen give young ladies on first dates, then gentlemen give flowers in order to be thought of as well intentioned, even if young ladies would rather be cooked a meal or sung a song. The inefficiency of conventional gift giving is the price one pays for communicating in a common language.

Noting that gift giving is circumscribed by convention helps explain why gift-giving rules are often enforced without tangible means or sanctions against deviance (see Caplow 1984). Conventions, like language, are "self-enforcing": an English speaker has no incentive to deviate from speaking English if others are speaking English, because English will communicate best - similarly with gift giving, which Caplow (1984) calls "a language that employs objects instead of words as its lexical elements."

\section{Inefficiency as the Price of Error in Guessing Tastes}

In mature relationships in which people know something about each other's tastes, the ideal gift seems to be one that a person likes but did not realize he liked. Good gift giving thus involves guessing a gift receiver's tastes, which often produces inefficiency.

Suppose a friend of mine is either a close friend, who knows my tastes well, or a casual friend, who does not know my tastes. Close friends can distinguish themselves from casual friends by giving me things I like. It is

${ }^{12}$ Cigars signal the birth of a child, of course. Schwartz (1967, p. 2) argues further that, if gifts convey the identities of givers, then cigar giving is a "display of masculinity," and he intimates exactly what "the new father's gift cigar symbolizes." 
useful for me to know whether a friend is a close or casual one because that knowledge guides my investment in our relationship (assuming that I prefer a relationship with a friend who knows my tastes), just as knowing whether a partner is willing to invest guides my investment. When my friend surprises me with an obscure Hüsker Dü recording, he reveals his knowledge of my tastes (along with his willingness to invest, as in the model above) with an efficient gift. His gifts are guesses about what I like, and sometimes these guesses will be wrong; gifts will be inefficient. This occasional inefficiency cannot be avoided by asking me what I like, because even a casual friend could do that. A close friend must guess at my tastes (and sometimes err) to distinguish himself from a casual friend.

The degree of inefficiency here need not be large, but there will often be some inefficiency. A person who knows my tastes quite well will buy gifts with efficiencies distributed around one. ${ }^{13}$ Half the time I will get inefficient gifts, but it is the thought (i.e., the effort to guess) that counts.

\section{EXPLAINING STYLIZED FACTS}

I have offered four explanations for why gifts are typically inefficient: (1) Inefficient gifts deter insincere gift collectors from entering into a relationship (this explanation also emerges from a formal analysis). (2) Gifts might signal several different things at once, and inefficiency is simply the price of multidimensional signaling. (3) Gifts often acquire their meanings from convention (as language does), and conventions need not be efficient. (4) When people want to signal their knowledge of a gift receiver's tastes by gift giving, they must guess the receiver's tastes. They sometimes guess wrong and give inefficient gifts the receiver does not like.

All these explanations begin with the simple notion that gifts are signals of some characteristic of the gift giver. Besides accounting for gift inefficiency in several ways, the signaling view, common to all four explanations, accommodates a wide range of evidence about gift-giving practices. For example, Caplow (1984) notes strict compliance with the rule that "a Christimas gift should . . . be scaled in economic value to the emotional value of the relationship." A DeBeers diamond ad reads, "2 months salary showed the future Mrs. Smith what the future will be like." These are remarkably clear statements of the signaling view (see inequalities [6] and [7], above). However, the signaling view does not

${ }^{13}$ Gifts with efficiencies greater than one are things that I did not know existed but that I would have bought if I knew about them. Thaler (1985) argues that many goods (liquor, chocolates) have efficiencies greater than one but are avoided because they are addictive-consuming a little leads to consumption of too much. Self-control can be maintained by only consuming these goods if they are given as gifts. 
explain many gift-giving practices, especially in families. I first discuss some stylized facts that fit the signaling view, and then I discuss stylized facts that do not fit.

\section{Why "It's the Thought That Counts"}

Any net cost of time, energy, or imagination is part of the signaling cost of a gift: the thought does count. Since such resources are nonsalvageable, they make gift giving inefficient (unless they substitute for the receiver's normal shopping). When vacationers bring back trinkets or send postcards to loved ones, they remind receivers at home that the giver is thinking about them, thus signaling by their thoughts (and possibly taking advantage of international price differences as well).

\section{Holidays as Focal Points for Simultaneous Gift Giving}

In the game-theoretic models, players are assumed to signal simultaneously, but they actually prefer to signal last (to avoid wasting gifts on a partner found to be unwilling). If gift giving is cooperative, simultaneity is assumed, but, if gift giving is noncooperative, it is useful to have some occasions on which it is commonly known that gifts should be exchanged to avoid the problem of who gives the gift first. ${ }^{14}$ Holidays serve this purpose well. They are "focal points," psychologically prominent points on which expectations converge. Of course, holidays serve other purposes too, and holidays do not always conveniently occur when simultaneous gift giving is needed-hence, the function of engagement rings, lavish wedding expenses, graduation gifts, and so on.

Holidays occur regularly, but the appropriate rate of signaling occasions should be as fast or slow as the rate of change in a partner's willingness. Teenage lovers might celebrate their "anniversary" every month, while long-married couples might only celebrate important anniversaries every five or 10 years.

\section{Birth Control and Premarriage Gift Giving}

Arguing purely by analogy with Dawkins's (1976) biological account, I suggest an important motive for gift giving from men to women before marriage is that marriage typically obligates a woman to bear children. Since it is very costly for women to bear children alone, and men are always tempted to desert the marriage after conception (arguing by anal-

${ }^{14}$ See Andrew Schotter's (1980, pp. 31-35) example of how the weekly calendar coordinated trade. 
ogy, remember), the premarriage gifts men give, such as an engagement ring, are like the nests that male birds build to pledge their fidelity to female birds. Of course, this story has changed dramatically in modern times, since marriage no longer obligates a woman, either socially or physically, to bear children (because of changing mores, modern birth control, and legalized abortion). Therefore, we might expect to see a decline in the traditional premarriage exchange of gifts from men to women, though important gifts (like diamonds) will still be useful to signal intentions on nonmarriage occasions. (Note that diamond companies have recently begun advertising that women should buy diamonds for their men.)

\section{Generic Gifts}

Between strangers or relatives whose tastes are unknown, conventional gifts that are exchanged often come from a small number of "generic" classes. Chocolates and candy, liquor, flowers, and jewelry are typical. Although I argued above that these gifts are simply conventional, there may be some reasons (besides historical accident) why these gifts, rather than others, became conventional.

Two features of these generic gifts make them good gifts. First, flowers and candy are perishable (though liquor and jewelry are not), so the recipient must often consume the gift more quickly than he would prefer, to avoid spoilage - hence, some inefficiency. Second, virtually everyone's utility for these products is continually increasing in price. ${ }^{15}$ Since quality is usually an increasing function of price, the giver can be fairly sure a high-cost version of one of these gifts is somewhat efficient (though not perfectly so), because the receiver will appreciate the quality (everyone likes fine chocolate), though not as much as he would like the equivalent amount of cash required to buy the high-cost version.

\section{Gift Giving in Business Relationships}

Often, long-term business or political relationships ${ }^{16}$ are economically identical to personal relationships, so we are not surprised by the "fictive friendships" that develop (see, e.g., Moore 1973). Anecdotal evidence

\footnotetext{
${ }^{15}$ Not so true of beer, which is not as appropriate a generic gift as wine or liquor, nor of caviar or art or many other possible classes of generic gifts.

${ }^{16}$ Posner (1980, p. 24) notes: "Gift-giving remains a custom in visits between heads of state; the lack of supranational government prevents the formal enforcement of promises and so makes the assessment of character and intentions more critical than in transactions enforceable by a public judiciary."
} 
suggests that courtship of top executives, often with material gift giving, is an important precursor to a successful corporate "marriage" (Wall Street Journal 1982). To explain involuntary labor-market unemployment, Akerlof $(1982$, 1984) suggests that hard work and above-market wages (which result in a shortage of jobs) are like an exchange of gifts between employers and employees who "develop sentiment" for each other. A similar idea dominates recent theories of product-quality assurance, in which firms buy inefficient gifts of advertising (Klein and Leffler 1981) or give gifts of high-quality goods sold at low-quality prices (Shapiro 1983) to signal their intention to produce high-quality goods.

When investments in a business relationship are transaction specific and costly, Williamson (1983) advocates the exchange of "hostages" (or hostage holding of capital commitments) that are valuable to the giver and worth little to the receiver (cf. Murrell [1982] on countertrade between countries). This is precisely inefficient gift giving, except that in business settings the cost of gifts needed to ensure each side's investment can be so huge that exchanging gifts permanently is extremely inefficient. Lending gifts seems more sensible (and incurs a signaling cost in the lost opportunity of using the gift while it is lent), so that if the relationship is severed agreeably the gifts can be retrieved and massive inefficiency is avoided.

Caplow (1982) notes that, at Christmas, employers routinely give money gifts to employees. These "gifts" are more like bonuses, which serve as incentive devices (cf. tipping of service employees), than like personal gifts of the sort I have considered.

\section{Some Anomalous Stylized Facts}

Some gift-giving practices are obviously inconsistent with the broad view that gifts are signals.

Why are price tags not left on gifts? - If gifts are signals, why are price tags not left on gifts? This is an important flaw in the signaling account. Perhaps keeping the price unknown cushions either the giver or receiver against disappointment if the gift cost much more or much less than we would prescribe (cf. Sabini and Silver [1982, pp. 107-23] on the protective ambiguity of flirting). In this regard, note Caplow's (1984) observation that parents rarely photograph their children with all their gifts unwrapped (though they often photograph children surrounded by wrapped gifts), because to do so "seems to invite the invidious comparison of gifts-and of the relationships they represent." Perhaps, by avoiding such comparison, whether by removing price tags or by making taboo the photographic comparison among gifts, givers and receivers can 
believe their relationships (as signaled by the gift) are better than they are. Put differently, the overt pricing of a relationship "taints affection with marketplace values" (Hemenway 1984, p. 59) and denies gift receivers the chance to believe that their relationships with gift givers are priceless.

Gift giving in families. - Since families are voluntary organizations formed by parents and having children who necessarily belong, there is no process of courtship to imply that gifts are signals. Instead, gifts from parents may shape or educate a child's tastes, or they may be control mechanisms to reward or punish children. ${ }^{17}$

As children grow up, parents' gifts to them become more and more efficient, thus resembling intergenerational transfers of wealth (as when parents give adult children gifts of cash) rather than signals. (Caplow [1982, p. 386] noted that at Christmas "nearly all money gifts between kin were intergenerational and 'downward.' ")

Children's gifts to parents - often charmingly homemade and ugly, with no direct utility value to parents-signal the child's affection but not exactly as in courtship. Instead, gift giving by children may give those children practice and familiarity with the norms of gift giving and with the process of imagining suitable gifts, so that as adults they can give gifts well.

In general, familial gift giving is more like primitive premarket exchange - as in the anthropological accounts, where gifts provide social insurance - than like signaling during courtship, so the inefficiencies that are important for signaling purposes need not be present in gift giving in the family.

When efficient gifts are appropriate.-When parents give cash as a wedding present to their children, that strikingly cold gift draws attention to the end of the parent-child relationship (for, if the relationship were intended to endure, an inefficient gift would be more appropriate). Perhaps this gesture blesses the marriage, signaling trust in the child's new spouse and acknowledging the validity of the child's new family. (Of course, this works heuristically, not precisely. Suppose parents and children understand the signaling analysis and follow a rule of thumb like "giving people exactly what they want is not right if you care about them." Then a deliberate cash gift is a polite way of saying, "We care about you less" - translated, "You are free to care less about us and more about your new family.")

${ }^{17}$ Hence, the invention of Santa Claus, who appears in a remarkable variety of cultures and is omniscient-Santa Claus "knows when you've been bad or good," as the song goes-so that his Christmas rewards can control child behavior better than parents can. The number of gifts a child receives, rather than the nature of the gifts, is the essence of the punishment or reward. See Schwartz (1967, p. 4). 
Gifts in memory of the dead are often deliberately efficient as well (such as contributions to a specified charity), perhaps because the forwardlooking relationship, signaled by inefficient gifts, is ended. One implication of this view (which seems false) is that people will not give gifts in memory of the dead unless they have ongoing relationships with surviving family members. Another implication (also wrong) is that the amount of contributions should be known to the surviving family members. Usually, the amounts are not publicized, perhaps for the same reasons that price tags are removed from gifts.

\section{CONCLUSION}

Gift giving is puzzling from an economic perspective because it is inefficient-givers spend money on gifts differently from the way receivers would - and it seems to be necessarily so. Other social sciencesanthropology and sociology, for instance-are full of explanations for gift giving, but these seem either too primitive or too complicated to be useful, and neither science describes a function for inefficiency (perhaps because neither science is as bothered by inefficiency as economists are).

However, the sociologists' insistence that gifts convey meaning is much like the economists' idea that gifts are "signals" of information-that is, the intentions of partners in a personal relationship. One can show formally that inefficiency is necessary because the value of gifts received subsidizes the cost of gifts given, and inefficient gifts deter partners who are unwilling to invest from simply collecting gifts. The variety of sociological explanations for gift giving suggests a second explanation, that gifts might serve multiple signaling purposes simultaneouslysignaling "willingness" to invest in a relationship, while also conveying meaning about the giver's tastes or identity or beliefs about the receiver. A third explanation for inefficiency is that the meaning of gifts is often conventional and arbitrary. Since convention is hard to change, once established, inefficient gift giving could persist. A fourth explanation is that gifts are signals of how much a gift giver knows about the receiver's tastes. If so, gifts are necessarily guesses about tastes that are sometimes wrong; therefore, gifts are sometimes inefficient.

The signaling view accounts for some stylized facts about modern practices of gift giving - the thought counts, holidays coordinate gift giving that is not naturally simultaneous, and so on. While the analysis seems especially appropriate for simple gift giving during courtship and in some business settings, it is not well suited to gift giving in families or to explaining pure charity. 


\section{APPENDIX: DETAILS OF THE SIGNALING AND INVESTMENT GAME}

Following the notation used in the main text and Harsanyi's (1967-68) definition of an incomplete-information game as one in which players have common knowledge about each other's (privately informed) types, I show the normal-form game matrix for the investment game in table A1. (Only 1's payoffs are shown, for simplicity; 2's are symmetric.)

While the role of investment may seem contrived and artificial, without an investment-theoretic definition of the relationship, players have no incentive to lie, so no signals are needed. By adding investment, we give a noninvesting player something to gain from riding free, so we provide a motive for some players to lie about their investment plans, and we create an information problem that signaling can solve.

In the game in table $\mathrm{A} 1,(W, I ; U, N)$ is always preferred to $(W, I ; U$, $I)$ - that is, $U$-type players never invest. $(W, I ; U, N)$ is preferred to $(W$, $N ; U, N)$, conditional on the other player choosing $(W, I ; U, N)$ (i.e., $W$ type players invest) if and only if their expected value from investing is above their expected value from not investing. For player 1, these expected values are

$$
\begin{gathered}
E V_{1}(I)=P_{2} R(W)+\left(1-P_{2}\right) Q(W) \\
E V_{1}(N)=P_{2} C(W)+\left(1-P_{2}\right) 0,
\end{gathered}
$$

so a $W$-type player will invest if and only if (iff) $E V_{1}(I)>E V_{1}(N)$, or

$$
P_{2}>-Q(W) /[R(W)-Q(W)-C(W)] \text {. }
$$

If we define the right-hand side as an "investment threshold" $t_{1}$ for player 1,1 invests iff $P_{2}>t_{1}$. A $W$-type player 2 invests iff a symmetric condition holds:

$$
P_{1}>-Q(W) /[R(W)-Q(W)-C(W)] \quad\left(=t_{2}\right) .
$$

The unique Bayesian Nash equilibria are these: ${ }^{18}$ (1) If both probabilities are above their thresholds $t_{1}$ and $t_{2}$, players choose $(W, I ; U, N)$. (2) If either probability is below its threshold, then one $W$-type player will not invest, so the other $W$-type player will not invest either, and the players both choose $(W, N ; U, N)$. If equilibrium (2) results, then signaling is needed.

${ }^{18}$ There are no mixed-strategy equilibria. $W$-types will always prefer $I$ to any mixedstrategy play of $I$ and $N$, conditional on their partner's probability being above its threshold. Intuitively, it seems that $U$-types might sometimes play $I$, if their probabilities are below their threshold, to coax their partner into playing $I$. However, $U$-types' sometimes playing $I$ is not a Nash equilibrium, since, if their mixed-strategy play does induce their partners to play $I$, the $U$-types then prefer playing $N$ with probability one. 


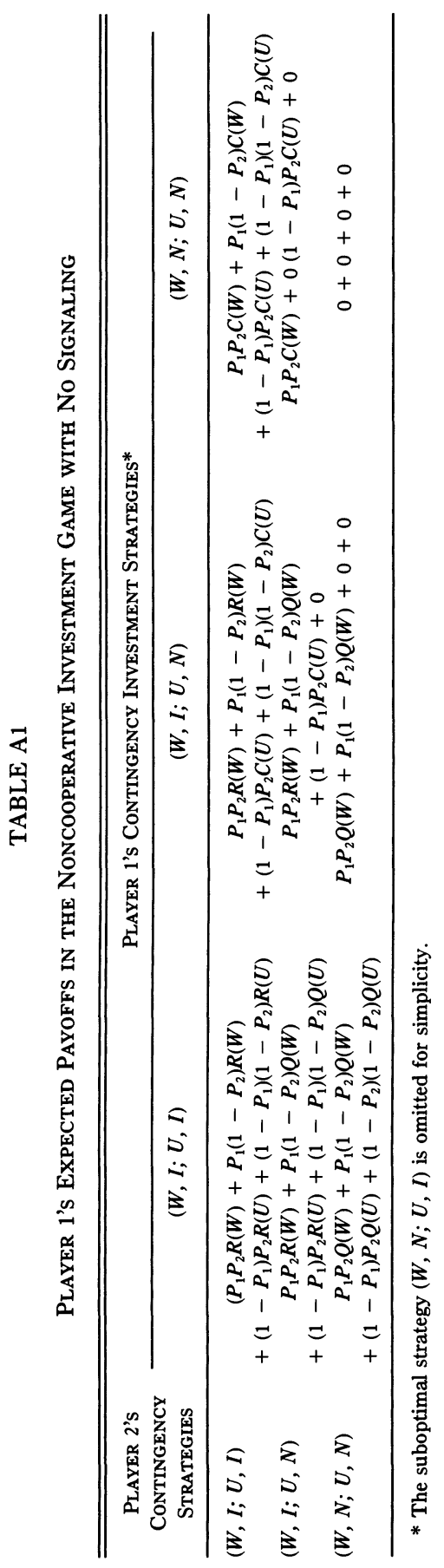


I follow the notation in the text for the costs $\left(G_{1}\right.$ and $\left.G_{2}\right)$ and efficiencies $\left(e_{1}, e_{2}\right)$ of gifts, carefully noting that all of 1 's receipts and costs have a marginal utility of income $L_{1}$ attached to them (and similarly for 2), which I omit for clarity. I also assume that utilities for gifts given, for gifts received, and for joint production are additively separable and independent between players. Adding within- or between-player utility interdependencies-such as gifts' having less utility cost when you are in love with the gift receiver-makes it easy to explain inefficient gift giving. I take the more challenging route.

In the two-stage signaling-investment game, players choose contingency strategies specifying whether they will invest in the signal depending on their type and invest in the relationship depending on whether the other person signaled. I assume initially that this two-period game is played noncooperatively, and I restrict their choice of strategies to giving gifts of size zero or $G_{1}$ (e.g., for player 1). There are a variety of purestrategy equilibria, depending on the exact values of the probabilities and utilities. (These are actually "sequential" equilibria of a specific sort, which rules out certain implausible Nash equilibria; see below.)

First, we can rule out "dishonest" signaling $(W, 0 ; U, G)$ : If dishonest signaling were part of a two-period Bayesian equilibrium, then a failure to signal in the first period would reveal a player as willing and would elicit investment from a willing partner in the second period. But then unwilling players would behave like willing players, not signaling in the first period to elicit second-period investment. So, dishonest signaling cannot be an equilibrium.

Ruling out that contingency strategy enables us to summarize the normal-form game in a series of $3 \times 3$ payoff matrices (tables A2-A4) showing only player 1's payoffs for simplicity. I study each possible equilibrium in turn. Figure 1 in the text summarizes how equilibria differ for different values of the $W$-type prior probabilities $P_{1}$ and $P_{2}$.

\section{Two-sided Signaling Equilibria (table A2)}

First, suppose that both prior probabilities $P_{1}$ and $P_{2}$ are below their thresholds, $t_{1}$ and $t_{2}$, so that if players do nothing to change their partners' beliefs, then no investment will result in the second period. A separating equilibrium results if both players choose $(W, G ; U, 0)$-only willing players invest in the signal, so players can be separated by whether they signal or not. Conditional on observing a signal, players infer with certainty that their partner is a $W$-type, so $W$-types happily invest in the second period (and each earns $R[W]$ ). If they observe no signal, players 
TABLE A2

Player 1's Expected Payoffs in the Noncooperative INVESTMENT-SIGNALING GAME

\begin{tabular}{lccc}
\hline \hline Player 2's & \multicolumn{3}{c}{ Player 1's Contingency Signaling Strategies } \\
\cline { 2 - 4 } $\begin{array}{c}\text { Contingency } \\
\text { Strategies }\end{array}$ & $(W, G ; U, G)$ & $(W, G ; U, 0)$ & $(W, 0 ; U, 0)$ \\
\hline$(W, G ; U, G):$ & & & \\
$\mathrm{S}$ & $-G_{1}+f_{1} G_{2}$ & $-P_{1} G_{1}+f_{1} G_{1}$ & $+f_{1} G_{2}$ \\
$\mathrm{I}$ & +0 & +0 & +0 \\
$(W, G ; U, 0):$ & & & \\
$\mathrm{S}$ & $-G_{1}+f_{1} P_{2} G_{2}$ & $-P_{1} G_{1}+f_{1} P_{2} G_{2}$ & $+f_{1} P_{2} G_{2}$ \\
$\mathrm{I}$ & +0 & $+P_{1} P_{2} R(W)$ & +0 \\
$(W, 0 ; U, 0):$ & $-G_{1}$ & $-P_{1} G_{1}$ & 0 \\
$\mathrm{~S}$ & +0 & +0 & +0 \\
$\mathrm{I}$ & & &
\end{tabular}

Note.-Assume $P_{1}<t_{1}$ and $P_{2}<t_{2}$. See also fig. 1. S and I denote payoffs from the signaling and investment parts of the game.

infer that their partner is unwilling, so they do not invest in the second period.

However, this is only an equilibrium if we make the signal expensive enough to deter $U$-types and cheap enough for $W$-types. Since a $U$-type player 1 earns an expected value of $P_{2} C(U)$ (and a $W$-type earns $P_{2} R[W]$ ) from player 2's investing, to make the signal too expensive for the $U$-type players and cheap enough for $W$-type players we require:

$$
\begin{aligned}
& P_{2} R(W)>G_{1}>P_{2} C(U), \\
& P_{1} R(W)>G_{2}>P_{1} C(U) .
\end{aligned}
$$

If the gift costs $G$ satisfy these bounds, then the separating equilibrium $(W, G ; U, 0)$ results.

There is no equilibrium mixed-strategy play here. Suppose a $U$-type player 1 bought the signal with probability $S$. When he did not buy the signal (a fraction 1-S of the time), he would earn nothing in the investment game. When he did buy the signal (a fraction $S$ of the time), his net earnings would be $S\left[-G_{1}+P_{2} C(U)\right]$, which is negative according to (A4). If the signal is expensive enough to deter a $U$-type from buying it all the time (i.e., if $G_{1}>P_{2} C[U]$ ), then it also deters the $U$-type from ever buying it. By similar reasoning, it seems that $W$-types will not play mixed strategies either. If a willing player 1 tries to economize by not signaling, then player 2 will not invest, and the $W$-type player 1 will lose out on a fraction of $P_{2} R(W)$ to save a fraction of $G_{1}$. By inequality (A4), this is a mistake, so a $W$-type always signals. 


\section{No-signaling Equilibrium with Investment (table A3)}

If both priors $P_{1}$ and $P_{2}$ are above their thresholds, $t_{1}$ and $t_{2}$, then players will invest in the second period even if they have learned nothing about their partner's type from the signaling. As a result, both types of players have no incentive to signal, and the result is a no-signaling equilibrium in which players do invest in the second period.

\section{No-signaling Equilibrium without Investment (table A4)}

Suppose one player's prior is below his threshold $-P_{1}<t_{1}$, for instance, so that 2 will not invest-but $P_{2}>t_{2}$, so that 1 will invest. Then, if a $W$ type player 1 does not signal, a $W$-type player 2 will not invest in the second period.

However, if a $W$-type player 1 does signal, his expected value from the two-period game is:

$$
E V_{1}\left(W, G_{1}\right)=P_{2} R(W)+\left(1-P_{2}\right) Q(W)-G_{1} .
$$

If we make the gifts as cheap as possible to satisfy (A3) and (A4), setting $G_{1}=P_{2} C(W)$, then it only pays for the $W$-type player 1 to signal if the expected value in (A6) is positive (since the $W$-type player 1 can always walk away from the game and earn zero). The expected value in (A6) is positive iff $P_{2}$ satisfies

$$
P_{2}>-Q(W) /[R(W)-Q(W)-C(U)] .
$$

(Notice that this threshold condition is almost exactly the same as the threshold condition [A2], except that $C[W]$ in equality [A2] is replaced by $C[U]$ in [A3].) Now, assuming $C(W)<C(U),{ }^{19}$ the threshold in (A7) is higher than the threshold $t_{2}$, so there is a range of $P_{2}$ in which a $W$-type player 1 is willing to invest but unwilling to pay the signaling cost to convince player 2 to invest. In this region (see fig. 1), no signaling (and, subsequently, no investment) takes place, and there is a symmetric region in which player 2 would like to signal but cannot afford to.

Note that if $C(W)>C(U)$, then the region in which players are willing to invest but not willing to signal disappears since the threshold in (A7) is below the threshold in (A2).

${ }^{19}$ To justify this logic, $C(U)$ and $C(W)$ must be comparable. This is a strong assumption, since a willing-type player and an unwilling-type player might be considered different people, and interpersonal comparisons of utility are notoriously problematic if not impossible. But here we can place the burden of comparability on the incomplete information structure of the game: because the players do not know the exact types of their partners, it seems reasonable to assume that players could agree on everything short of those exact types, thus allowing hypothetical interval comparisons of all the utilities in definitions (4) and (5) in the text. 


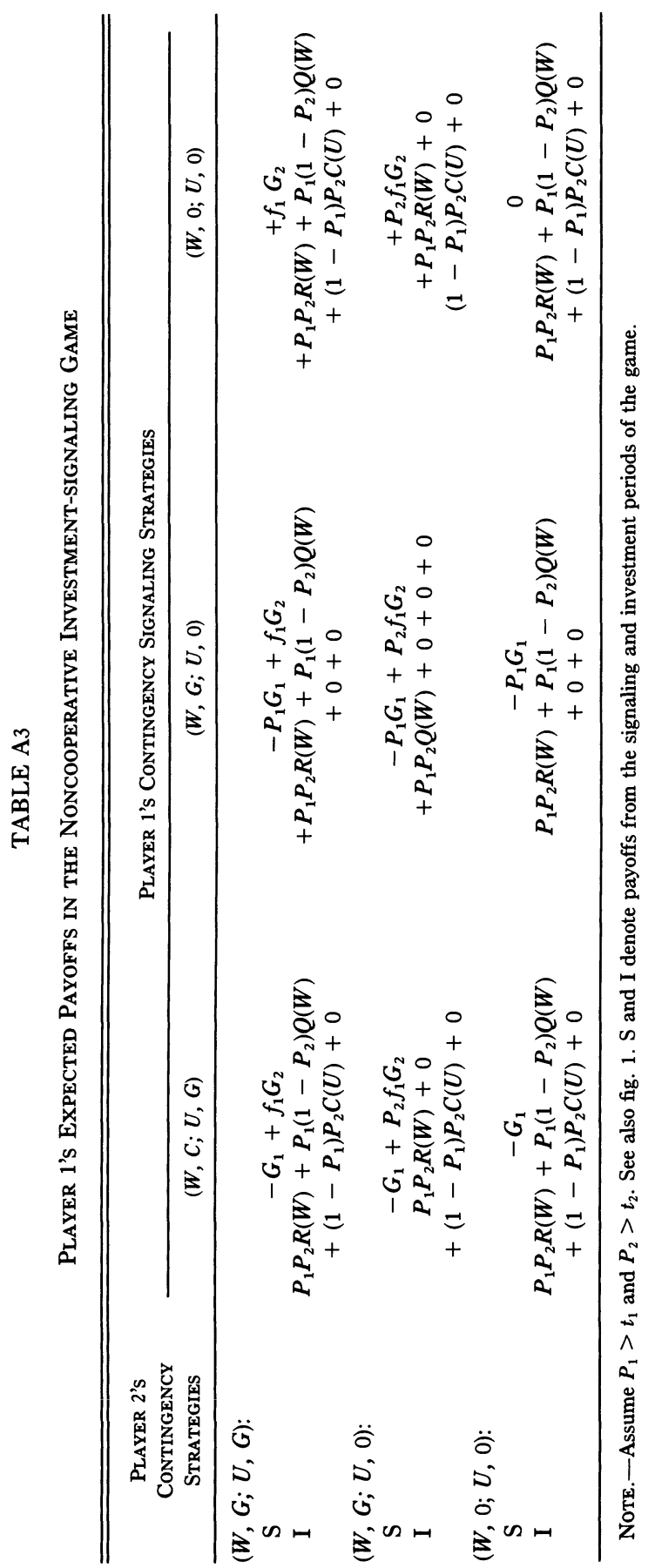


American Journal of Sociology

TABLE A4

Player 1's Expected Payoffs in the Noncooperative Investment-signaling

GAME

\begin{tabular}{lccc}
\hline \hline \multirow{2}{*}{$\begin{array}{c}\text { Player 2's } \\
\text { Contingency } \\
\text { Strategies }\end{array}$} & \multicolumn{3}{c}{ Player 1's Contingency Signaling Strategies } \\
\cline { 2 - 4 }$(W, G ; U, G)$ & $(W, G ; U, 0)$ & $(W, 0 ; U, 0)$ \\
\hline S $G ; U, G):$ & & $-P_{1} G_{1}+f_{1} G_{2}$ & \\
$\mathrm{~S}$ & $-G_{1}+f_{1} G_{2}$ & $+f_{1}$ & $+f_{2}$ \\
$\mathrm{I}$ & +0 & $+P_{1} P_{2} R(W)+P_{1}\left(1-P_{2}\right) Q(W)$ & +0 \\
& & & \\
$(W, G ; U, 0):$ & $-G_{1}+P_{1} f_{1} G_{2}$ & $-P_{1} G_{1}+P_{2} f_{1} G_{2}$ & $+P_{2} f_{1} G_{2}$ \\
$\mathrm{~S}$ & +0 & $+P_{1} P_{2} R(W)+0$ & +0 \\
$\mathrm{I}$ & & $+0+0$ & \\
& & $-P_{1} G_{1}$ & 0 \\
$(W, 0 ; U, 0):$ & $-G_{1}$ & $P_{1} P_{2} R(W)+P_{1}\left(1-P_{2}\right) Q(W)$ & +0 \\
$\mathrm{~S}$ & +0 & $+0+0$ & \\
I & &
\end{tabular}

Note.-Assume $P_{1}<t_{1}$ and $P_{2}>t_{2}$. See also fig. 1. S and I denote payoffs from the signaling and investment periods of the game.

By arguments analogous to those for the two cases above, there are no mixed-strategy equilibria here either. $U$-types cannot afford to signal with any probability, and $W$-types will never want to economize on signaling.

\section{One-sided Signaling Equilibria (table A4)}

Suppose $P_{2}$ is above the investment threshold $t_{2}$ and above the affordability threshold in (A7) but $P_{1}$ is below $t_{1}$. Then the low prior $P_{1}$ makes player 2 afraid to invest in the second period without a signal from player 1 , so a $W$-type player 1 wants to signal player 2 (and can afford to). A "one-sided" signaling equilibrium results (see fig. 1) in which 1 signals to 2 if 2 is likely to be willing but 1 is unlikely, or vice versa. (Intuitively, the player who is most likely to be a $U$-type must signal to his partner. The sincere must convince the skeptic, not the other way around.)

\section{Nash versus Sequential (and Perfect) Equilibrium}

I have called the four kinds of equilibria above Nash equilibria, but this is not quite accurate. In dynamic games, Nash equilibria are often perverse because they involve threats that are not credible. In the no-signaling region, for example (where the priors $P_{1}$ and $P_{2}$ are above the investment thresholds), the strategy $(W, G ; U, 0)$ for both players is one Nash equilib- 
rium, because if everyone thinks he must give a gift to attract investment, he will give gifts. But what if many $W$-type players did not give gifts? Presumably, they would still attract investment, so the threat that is implicit in the equilibrium, to invest only if given a gift, is not credible.

A common way to rule out such equilibria is to test them for "subgame perfection"- that is, to ask whether an equilibrium is an equilibrium in every possible subgame from period $t$ to the end, even for subgames that are not expected to be reached (Selten 1975). An equilibrium is "sequential" if it is subgame perfect (or "trembling-hand perfect," if no subgames exist) and if a few other technical requirements are satisfied (see Kreps and Wilson 1982). Many Nash equilibria are not sequential (like [ $W, G$; $U, 0]$ in the above-threshold region), but all sequential equilibria are Nash ones. All the equilibria described above are sequential. However, there may be other sequential equilibria that I am ignoring.

\section{The Efficiency of Equilibrium Gifts}

The signaling equilibria, if they exist, restrict how costly gift signals $G_{1}$ and $G_{2}$ must be (to satisfy inequalities [A4] and [A5]), but no natural limits on gift efficiency emerge. As discussed in the text, we can derive efficiency bounds by expanding the game to include small costs $T_{1}$ and $T_{2}$ (with marginal utilities of income attached) of entering the first-period signaling game. These costs, and appropriate efficiency bounds, discourage $U$-types from entering the game. However, a $W$-type player 1 has a net expected value of $-T_{1}-G_{1}+e_{1} G_{2} P_{2}+P_{2} R(W)$. This expression is positive if $e_{1}$ just satisfies the threshold (8) because then the first and third terms cancel out, and, since $G_{1}=P_{2} C(U)$, it is less than $P_{2} R(W)$ (because $R[W]>C[U]$ by assumption).

Inefficient gifts help deter, but they can hurt willing players. A $W$-type player 1 , for instance, earns $-G_{1}+P_{2} G_{2}$ in net gift receipts if efficient gifts are given, but, if the efficiency thresholds in (8) and (9) are enforced and a $U$-type player 2 does not enter the game, then a $W$-type player 1 earns expected net gift receipts of $P_{2}\left(-G_{1}+e_{1} G_{2}\right)-T_{1}$ and expected relationship gains of $P_{2} R(W)$. (These net gains are always positive, so $W$ types are not discouraged from entering the game as $U$-types are, assuming $e$ 's are chosen to make [8] and [9] bind. Then the terms $P_{2} e_{1} G_{2}$ and $-T_{1}$ cancel, and $P_{2} R[W]-P_{2} G_{1}$ is positive.) Assuming the efficiency values are as large as possible within the bounds (8) and (9), the $W$-type player 1 prefers the inefficient-gift scheme if $P_{2} /\left(1-P_{2}\right)<G_{1} / G_{2}$. Combining this inequality for $W$-type player 2 with an analogous condition for player 1 yields condition (10) in the text.

Note that we can smooth this discontinuous jump from preferring inefficient to efficient gift giving that is embodied in (A10) by supposing 
that there are probability distributions of the costs $T_{1}$ and $T_{2}$, so that gifts with differing degrees of efficiency will screen out differing numbers of unwilling-type gift collectors. Then, the optimal efficiency level will gradually rise as the probabilities $P_{1}$ and $P_{2}$ rise.

\section{Inefficiency Signals If Gift Costs Are Identical}

Suppose we restrict the costs of gifts given by $W$-types and $U$-types to being identical, as if we were enforcing some social norm that requires suitors to give a gift of a certain cost during courtship. If players can then specify the degree of inefficiency in the gift they will receive, players can signal their types by asking for efficient gifts ( $U$-types) or for inefficient gifts ( $W$-types). This is the formalization of my argument that the opportunity cost of an inefficient gift to a receiver is itself a signal.

Suppose the equilibrium efficiencies are $e_{u}$ and $e_{w}$ (and suppose they are different, so that players' choices of efficiency signal their types). The $U$ type player 1 can choose $e_{u}$ and earn

$$
-G_{1}+e_{u} G_{2},
$$

or choose $e_{w}$ and earn

$$
-G_{1}+e_{w} G_{2}+P_{2} C(U)
$$

(and similarly for player 2). The $W$-type player 1 can choose $e_{u}$ and earn

$$
-G_{1}+e_{u} G_{2},
$$

or choose $e_{w}$ and earn

$$
-G_{1}+e_{w} G_{2}+P_{2} R(W) .
$$

For players to signal their true types, (A8) must be greater than (A9), and (A11) must be greater than (A10). For player 1, for instance, this implies

$$
P_{2} R(W)>G_{2}\left(e_{u}-e_{w}\right)>P_{2} C(U),
$$

and, since both expressions on the right and the left of the inequality are positive, this implies $e_{u}$ must be greater than $e_{w}$. That is, players can be distinguished by whether they ask for practical gifts they can use ("money, please" or "let me pick my favorite restaurant") or for frivolous gifts ("give me something charming," "surprise me").

\section{Gift Giving in a Cooperative Game}

Cooperation-defined in game theory as the ability to communicate about and enforce the strategy choices of players-seems realistic in many gift-giving situations: partners do talk about gift giving in relation- 
ships, including discussions of gift costs and whether gifts should be efficient or not. Furthermore, the assumption of cooperation is probably best suited to mature relationships where $P_{1}$ and $P_{2}$ are presumably above their thresholds (else, the relationship would not have lasted) and where signaling does not take place noncooperatively.

Cooperative games with incomplete information are not as directly solved as noncooperative games, since there is no simple leap like Harsanyi's (1967-68) to transform incomplete-information games into complicated complete-information games. Instead, I consider solutions to cooperative games with incomplete information with the properties of "feasibility" and "incentive efficiency." 20

A feasible solution satisfies two criteria: individual rationality and incentive compatibility. Solutions must be individually rational in the sense that each player has a positive expected value from the solution. Incentive compatibility means that players must play honestly, given their types (i.e., they should not prefer pretending to be another type). We assume that a solution is actually implemented using a "direct mechanism": players agree on a solution that prescribes a strategy for each of the player's possible types, then they report a type (though not necessarily their true type) to a mediator, who implements the solution and executes strategy choices based on the type reports. While the direct mechanism sounds contrived, by the "revelation principle" (Myerson 1979), any Bayesian equilibrium of the gift-giving game has an equivalent solution, implemented by a direct mechanism that yields the same outcomes. Thus, by studying only solutions implemented with direct mechanisms, we are actually studying all equilibria of the game.

An incentive-efficient solution is one that yields expected values for each player (and each possible type) that could not be improved on by another solution for every player and type. (This definition of efficiency, called "interim incentive-efficiency" by Holmstrom and Myerson [1983], is a straightforward extension of Pareto optimality, treating each player's possible type as a separate player. Note the distinction between incentive efficiency, which is a property of possible solutions considered by the players, and the efficiency of gifts, which is the value of those gifts to recipients.)

I shall first analyze the gift-giving game, played cooperatively, for feasible solutions; then I shall use incentive efficiency as a criterion to suggest one particularly plausible class of solutions. It will turn out that the class of incentive-efficient solutions is the same as the "two-sided, gift-

${ }^{20}$ One might also ask whether solution concepts are "equitable," in order to prescribe a solution or to predict how players with equal bargaining ability will bargain. See Myerson (1983, 1984). 
giving investment" equilibrium-with no implications for efficiency levels $e_{1}$ and $e_{2}$-in the noncooperative game.

\section{Feasibility Constraints on Cooperative Solutions}

By cooperation, I mean that the players agree on a vector of gift costs and efficiencies that depend on a player's type, then they report their types (possibly falsely) to the mediator, who makes them buy the gifts and exchange them. I shall restrict our choice of cooperative solutions to those that signal perfectly each player's type when the gifts are bought and exchanged; so the investment game that follows the gift giving is a straightforward complete-information game in which $W$-types only invest if their partners are $W$-types.

Let the gift costs and efficiencies for player 1 be written $\left(W, G_{1}^{w}, e_{1}^{w} ; U\right.$, $\left.G_{1}^{u}, e_{1}^{u}\right)$, and similarly for player 2. (Notice that players choose the efficiency of the gift they will recieve, $e_{1}$ for player 1 , not the efficiency of the gifts they give.) The players' expected payoffs from the game, depending on their types and assuming that they report their types honestly and that the solution reveals each player's type, are:

$$
\begin{aligned}
& E V_{1}(W)=-G_{1}^{w}+P_{2}\left[e_{1}^{w} G_{2}^{w}+R(W)\right]+\left(1-P_{2}\right)\left(e_{1}^{w} G_{2}^{u}\right) \\
& E V_{1}(U)=-G_{1}^{u}+P_{2}\left(e_{1}^{u} G_{2}^{w}\right)+\left(1-P_{2}\right)\left(e_{1}^{u} G_{2}^{u}\right) ; \\
& E V_{2}(W)=-G_{2}^{w}+P_{1}\left[e_{2}^{w} G_{1}^{w}+R(W)\right]+\left(1-P_{1}\right)\left(e_{2}^{w} G_{1}^{u}\right) \\
& E V_{2}(U)=-G_{2}^{u}+P_{1}\left(e_{2}^{u} G_{1}^{w}\right)+\left(1-P_{1}\right)\left(e_{2}^{u} G_{1}^{u}\right) .
\end{aligned}
$$

The individual rationality constraints simply require that each of these expected values is positive. The incentive-compatibility constraints require that players prefer reporting their true types, so that the honestreporting expected values in (A13) and (A14) are greater than the expected values that result from lying (assuming everyone else reports honestly). For player 1, for instance, incentive compatibility implies that

$$
\begin{aligned}
& E V_{1}(W)>-G_{1}^{u}+P_{2}\left(e_{1}^{u} G_{2}^{w}\right)+\left(1-P_{2}\right)\left(e_{1}^{u} G_{2}^{u}\right) \\
& E V_{1}(U)>-G_{1}^{w}+P_{2}\left[e_{1}^{w} G_{2}^{w}+C(U)\right]+\left(1-P_{2}\right)\left(e_{1}^{w} G_{2}^{u}\right),
\end{aligned}
$$

(where $E V_{1}[W]$ and $E V_{1}[U]$ are the expected values from [A13], and similarly for player 2). The feasibility constraints form a system of eight inequalities - four individual rationality $(I R)$ constraints, one for each possible player type, and four incentive-compatibility $(I C)$ constraints.

First, I shall suppose that both players give perfectly efficient gifts $\left(e^{u}=e^{w}=1\right)$, and I shall calculate what gift costs are required for the eight constraints to be met. 
With the $e$ 's equal to one, the $I R$ constraints for player 1 are:

$$
\begin{aligned}
& 0<-G_{1}^{w}+G_{2}^{u}+P_{2}\left(G_{2}^{w}-G_{2}^{u}\right)+P_{2} R(W) \\
& 0<-G_{1}^{u}+G_{2}^{u}+P_{2}\left(G_{2}^{w}-G_{2}^{u}\right) ; \\
& 0<G_{1}^{u}-G_{1}^{w}+P_{2} R(W) \\
& 0<-G_{1}^{u}+G_{1}^{w}-P_{2} C(U) .
\end{aligned}
$$

If we let the $U$-type $I C$ constraints be binding for both players (which makes $W$-type the best off, as I show clearly below), we can eventually show after much tedious algebra that a solution exists, in which

$$
\begin{aligned}
& G_{2}^{w}=G_{2}^{u}+P_{1} C(U) \\
& G_{1}^{w}=G_{1}^{u}+P_{2} C(U) .
\end{aligned}
$$

Thus, players exchange perfectly efficient gifts, but the sizes of the gifts players give distinguish their willingness.

This solution is incentive efficient as well as feasible. (That is, there is no solution that makes all players better off. Indeed, every other feasible solution makes some players worse off.) To see this, I shall reframe the problem and consider alternative solutions one at a time. If I denote players' expected utilities from both gift giving and investment as $V_{1}^{w}$, and so on, then the constraints above are simply constraints on utilities. Remembering what those utilities are, I can rewrite the $I C$ and $I R$ constraints as

$$
\begin{aligned}
& V_{1}^{w} \geq 0 \quad(I R) \\
& V_{1}^{u} \geq 0 \\
& V_{1}^{w} \geq V_{1}^{u} \quad(I C) \\
& V_{1}^{w} \leq V_{1}^{u}-P_{2} C(U)+P_{2} R(W)
\end{aligned}
$$

and

$$
\begin{aligned}
& V_{2}^{w} \geq 0 \quad(I R) \\
& V_{2}^{u} \geq 0 \\
& V_{2}^{w} \geq V_{2}^{u} \quad(I C) \\
& V_{2}^{w} \leq V_{2}^{u}-P_{1} C(U)+P_{1} R(W) .
\end{aligned}
$$

First, suppose the gifts have equal efficiency, which is less than one (i.e., $e^{u}=e^{w}=c, c<1$ ), and compare this with the case analyzed above, in which $e^{u}=e^{w}=1$. The IC constraints in (A15) are completely unchanged by lowering the efficiency from one to $c$, as long as efficiencies are equal (because only the difference in the efficiencies enters the $I C$ 
constraints), but both players' utilities are lower (since the utilities are an increasing linear function of the $e^{\prime}$ s). Thus, the solution in which the $e^{w}$ $=e^{u}=c$ is not incentive efficient. Now compare the case where $e^{w}=e^{u}$ $=1$ with the case where gifts have differing efficiencies, with $e^{w}=1$ and $e^{u}=c(c<1)$. By lowering $e^{u}$, we lower $V^{u}$ (by [A13] and [A14]), and $V^{w}$ must also be lower (by the second $I C$ constraint), to discourage a $U$-type from pretending to be a $W$-type. This solution is thus worse for everyone than the solution $e^{u}=e^{w}=1$. Finally, consider the case where $e^{w}=c(c$ $<1$ ) and $e^{u}=1$. (This corresponds to the game considered above, in which players' gift costs are identical, but they can signal willingness by accepting low-efficiency gifts.) Here, we have lowered $V^{w}$ directly and left $V^{u}$ unchanged (unless it is lowered by the first $I C$ constraint), so this solution is also worse than $e^{w}=e^{u}=1$.

Thus, by the process of elimination, we see that the solution $e^{w}=e^{u}$ $=1$ is incentive efficient. The intuition behind this result is that, by lowering any player's gift efficiency, we certainly make that player worse off, and we either make the other-type player no better off, or we make that player worse off because the $I C$ constraints force player's utilities to be not far apart.

Note that the gift costs in (A18) are almost exactly the same as the (lower-bounded) gift costs from the noncooperative game (see [A4] and [A5]), except that we have let $G_{u}$ be positive in the cooperative game and we restricted it to equalizing zero in the noncooperative game. The important point is that a $W$-type player 1's gift must cost $P_{2} C(U)$ more than a $U$-type player 1's gift. Otherwise, the two games are exactly the same, except the two-sided gift-giving solution is incentive efficient for any probabilities in the cooperative game, while it is only an equilibrium for certain probabilities in the noncooperative game.

\section{REFERENCES}

Akerlof, George A. 1980. "A Theory of Social Custom of Which Unemployment May Be One Consequence." Quarterly Journal of Economics 94:749-75.

. 1982. "Labor Contracts as Partial Gift Exchange." Quarterly Journal of Economics 47:543-69.

. 1984. "Gift Exchange and Efficiency-Wage Theory: Four Views." American Economic Review 74:79-83.

Arrow, Kenneth J. 1972. "Gifts and Exchanges." Philosophy and Public Affairs 1:343-62.

Aumann, Robert. 1976. "Agreeing to Disagree." Annals of Statistics 4:1236-39.

Barnett, H. G. 1938. "The Nature of the Potlatch." American Anthropologist 40:34958.

Belshaw, Cyril S. 1965. Traditional Exchange and Modern Markets. Englewood Cliffs, N.J.: Prentice-Hall.

Boas, Franz. 1895. "The Social Organization and the Secret Societies of the Kwakiutl 
Indians." In Annual Report of the Smithsonian Institution for 1895. Washington, D.C.: Smithsonian Institution.

. 1920. "The Social Organization of the Kwakiutl." American Anthropologist 22:111-26.

Caplow, Theodore. 1982. "Christmas Gifts and Kin Networks." American Sociological Review 47:383-92.

. 1984. "Rule Enforcement without Visible Means: Christmas Gift Giving in Middletown." American Journal of Sociology 89:1306-23.

David, Paul. 1985. "Clio and the Economics of QWERTY." American Economic Review 75:332-37.

Dawkins, Richard. 1976. The Selfish Gene. New York: Oxford University Press.

Douglas, Mary, and Baron Isherwood. 1978. The World of Goods. New York: Basic.

Fama, Eugene F. 1980. "Agency Problems and the Theory of the Firm." Journal of Political Economy 88:288-307.

Harsanyi, John C. 1967-68. "Games with Incomplete Information Played by 'Bayesian' Players." Management Science 14:159-89, 320-34, 486-502.

Hemenway, David. 1984. Prices and Choices: Microeconomic Vignettes. Cambridge, Mass.: Ballinger.

Holmstrom, B., and Robert B. Myerson. 1983. "Efficient and Durable Decision Rules with Incomplete Information." Econometrica 51:1799-1819.

Klein, B., and K. B. Leffler. 1981. "The Role of Market Forces in Assuring Contractual Performance." Journal of Political Economy 89:615-41.

Kreps, David M., and Robert Wilson. 1982. "Sequential Equilibria." Econometrica 50:863-94.

Kurz, Mordecai. 1978. "Altruism as an Outcome of Social Interaction." American Economic Review 68:216-22.

Lewis, David K. 1969. Convention: A Philosophical Study. Cambridge, Mass.: Harvard University Press.

Lewontin, Richard C. 1979. "Sociobiology as an Adaptationist Program." Behavioral Science 24:5-14.

Luce, R. Duncan, and Howard Raiffa. 1957. Games and Decisions. New York: Wiley.

Malinowski, Bronislaw. 1932. Argonauts of the Western Pacific. London: Routledge \& Kegan Paul.

Mauss, Marcel. 1967. The Gift: Forms and Functions of Exchange in Archaic Societies. New York: Norton.

Maynard Smith, J. 1974. "The Theory of Games and the Evolution of Animal Conflicts." Journal of Theoretical Biology 47:209-19.

Moore, Sally F. 1973. "Law and Social Change: The Semi-Autonomous Social Field as an Appropriate Subject of Study." Law and Society Review 723-29.

Murrell, Peter. 1982. "Product Quality, Market Signaling, and the Development of East-West Trade." Economic Inquiry 20:589-600.

Myerson, Roger B. 1979. "Incentive Compatibility and the Bargaining Problem." Econometrica 47:61-73.

97.

- 1984. "Two-Person Bargaining Problems with Incomplete Information." Econometrica 52:461-87.

Posner, Richard A. 1980. "A Theory of Primitive Society, with Special References to Law." Journal of Law and Economics 23:1-53.

Rothschild, Michael, and Joseph Stiglitz. 1976. "Equilibrium in Competitive Insurance Markets: An Essay in the Economics of Imperfect Information." Quarterly Journal of Economics 90:629-49. 


\section{American Journal of Sociology}

Sabini, John, and Maury Silver. 1982. Moralities of Everyday Life. New York: Oxford University Press.

Schotter, Andrew. 1980. The Economic Theory of Social Institutions. New York: Cambridge University Press.

Schwartz, Barry. 1967. "The Social Psychology of the Gift." American Journal of Sociology 73:1-11.

Selten, Reinhard. 1975. "Reexamination of the Perfectness Concept for Equilibrium Points in Extensive Games." International Journal of Game Theory 4:25-55.

Shapiro, C. 1983. "Premium for High Quality as Returns to Reputations." Quarterly Journal of Economics 98:659-80.

Spence, A. Michael. 1974. Market Signaling: Information Transfer in Hiring and Related Screening Processes. Cambridge, Mass.: Harvard University Press.

Thaler, Richard. 1985. "Mental Accounting and Consumer Choice." Marketing Science 4:199-214.

Thompson, Michael. 1979. Rubbish Theory: The Creation and Destruction of Value. Oxford: Oxford University Press.

Titmuss, Richard M. 1971. The Gift Relationship: From Human Blood to Social Policy. New York: Pantheon.

Veblen, Thorstein. 1934. Theory of the Leisure Class. New York: Modern Library. von Neumann, John, and Oskar Morgenstern. 1953. Theory of Games and Economic Behavior, 3d ed. Princeton, N.J.: Princeton University Press.

Wall Street Journal. 1982. "In Mergers, Manners Can Matter a Lot." Wall Street Journal, October 4, pp. $1+$.

Williamson, Oliver F. 1983. "Credible Commitments: Using Hostages to Support Exchange." American Economic Review 83:519-40. 